\title{
Correction to: Meaning in Life, Religious Coping, and Loneliness During the Coronavirus Health Crisis in Turkey
}

\author{
Murat Yıldırım ${ }^{1,2}$ - Muhammed Kızılgeçit ${ }^{3} \cdot$ İsmail Seçer $^{3} \cdot$ Fuat Karabulut $^{3}$. \\ Yasemin Angın ${ }^{3}$. Abdullah Dağcı ${ }^{4}$ - Muhammed Enes Vural ${ }^{5}$. \\ Nurun Nisa Bayram ${ }^{3}$. Murat Çinici ${ }^{3}$
}

Published online: 30 January 2021

(c) Springer Science+Business Media, LLC, part of Springer Nature 2021

\section{Correction to: Journal of Religion and Health https://doi.org/10.1007/s10943-020-01173-7}

The original publication of the article was inadvertently published with wrong affiliation link for the co-author. The correct affiliation for the co-author, "Abdullah Dağcı" should be "Psychology of Religion, Divinity Faculty, Ankara University, Ankara, Turkey". This has been corrected with this erratum.

The original article has been corrected.

Publisher's Note Springer Nature remains neutral with regard to jurisdictional claims in published maps and institutional affiliations.

The original article can be found online at https://doi.org/10.1007/s10943-020-01173-7.

\section{Murat Yıldırım}

muratyildirim@agri.edu.tr; muratyildirimphd@gmail.com

1 Department of Psychology, Faculty of Science and Letters, Ağrı İbrahim Çeçen University, Erzurum Yolu 4 Km 04100, Merkez, Ağrı, Turkey

2 University of Leicester, Leicester, UK

3 Atatürk University, Erzurum, Turkey

4 Psychology of Religion, Divinity Faculty, Ankara University, Ankara, Turkey

$5 \quad$ Recep Tayyip Erdoğan University, Rize, Turkey 